\title{
Size, muscle metabolic capacities and escape response behaviour in the giant scallop
}

\author{
A.-A. Labrecque ${ }^{*}$, H. Guderley \\ Département de biologie, Université Laval, Québec, Québec G1V 0A6, Canada
}

\begin{abstract}
Placopecten magellanicus start their lives as free-living veligers, then become byssally attached juveniles, mobile young adults and finally generally sedentary large adults. Although biomechanical considerations help explain this size dependence of swimming activity, the patterns of muscle use and the physiological capacities of the adductor muscle could change with size. Measurements of in vivo force production (in 2004) and muscle metabolic capacities (in 2008) were used to assess how P. magellanicus (îles-de-la-Madeleine, $47^{\circ} 23^{\prime} \mathrm{N}, 61^{\circ} 52^{\prime} \mathrm{W}$ ) of 30 to $98 \mathrm{~mm}$ in shell height $(\mathrm{SH})$ use the adductor muscle during escape responses. Principal components analysis of escape response behaviours revealed that parameters associated with endurance and phasic contraction frequency were associated on the first 2 axes, whereas measures of force production were linked on the third axis. Individual scores from the first and third principal components showed a significant size dependence, with values first increasing and then decreasing with SH. Scallop size influenced escape response endurance, clap numbers and force production in a similar fashion. These metrics of muscle use generally peaked at SH $\sim 70 \mathrm{~mm}$. Physiological attributes, including muscle enzymatic activities and phosphoarginine content, peaked at $\mathrm{SH} \sim 60 \mathrm{~mm}$. Although the gonadosomatic index increased with size, it did not explain the scaling of escape response behaviours or muscle metabolic capacities. Ecological considerations, particularly predation risk, may explain this allometric pattern.
\end{abstract}

KEY WORDS: Size $\cdot$ Muscle metabolic capacities $\cdot$ Scallop $\cdot$ Placopecten magellanicus Resale or republication not permitted without written consent of the publisher

\section{INTRODUCTION}

For most animals, locomotion is required to acquire food, to escape predators and to search for partners. At the same time, muscle is the largest pool of macromolecules. Thus, at any point in its life, an animal's locomotor performance should reflect a compromise between these roles of muscle. As small animals mainly grow, while larger animals reproduce, the compromise will change with size and age. Further, animal size and shape influence how the major physical forces, gravity, drag, lift and thrust, will influence movement. While gravity and drag reduce movement, lift and thrust help. As mentioned by Gould (1971), a striking feature of organisms is their ability to deal with different biomechanical requirements at various stages of their life cycles.
The size dependence (or scaling) of organismal structure and function is the focus of a large body of literature. This size dependence is rarely isometric, and the reason for the allometric relationships between body size and functional traits is the subject of considerable debate (Hochachka \& Somero 2002). Basal rates of oxygen uptake expressed relative to body mass decrease with size in all phylogenetic groups studied (Wilkie 1977). Part of this pattern is due to the decreasing relative size of highly aerobic organs (Goolish 1991) and part is due to intrinsic changes in tissue metabolic requirements (Hulbert \& Else 2005). In parallel with the size dependence of basal metabolic requirements, mass-specific tissue aerobic capacities, as estimated by activities of mitochondrial enzymes, decrease with body size in a wide range of organisms. In contrast, the glycolytic capacity of muscle increases with size in fish and marine mammals (Somero \& Chil- 
dress 1980, Emmett \& Hochachka 1981, Childress \& Somero 1990). The greater drag experienced by larger fish and marine mammals during high-speed swimming is thought to have favoured greater glycolytic power development. This unusual metabolic scaling reflects the constraints of aquatic locomotion.

Scallops avoid predators with a dramatic swimming response (Thomas \& Gruffydd 1971, Legault \& Himmelman 1993). Swimming is initiated by the expulsion of jets of water from the mantle cavity by rapid contractions of the adductor muscle, alternating with valve opening caused by decompression of the hinge ligament (Trueman 1953, Alexander 1966, Brand 1991). During scallop swimming, bursts of contraction by the phasic adductor muscle produce most of the power. The contraction of the tonic adductor allows prolonged valve closure or maintenance of a constant valve opening. Tonic contractions between bursts of phasic contractions permit metabolic recuperation of the phasic muscle (Pérez et al. 2008).

The swimming behaviour of Placopecten magellanicus changes with size. Diving observations by Caddy (1968, 1972) identified 3 phases: a sessile stage (1 to $30 \mathrm{~mm}$ in shell height [SH]), a mobile stage (30 to $100 \mathrm{~mm})$ and a more sedentary stage (>100 mm). $P$. magellanicus' swimming style also varies with size. Small scallops tend to rise in the water column and rarely succeed in swimming horizontally. Scallops of intermediate size rise in a rectilinear motion and can swim steadily for several meters (Caddy 1968, Dadswell \& Weihs 1990, Manuel \& Dadswell 1993). Larger scallops, restrained by their heavy shells, only swim short distances. P. magellanicus of intermediate size $(40$ to $80 \mathrm{~mm})$ are the fastest swimmers and possess the greatest hydrodynamic efficiency (Dadswell \& Weihs 1990).

Although biomechanical and morphometric traits are important in establishing the swimming capacities of scallops, locomotor performance may also reflect muscle metabolic capacities and patterns of muscle use. The changes in swimming style with size suggest that muscles may be used differently as scallops grow. The changing difficulty of generating lift could favour higher numbers and frequencies of phasic contractions in small scallops. Reliance on tonic contractions could increase with size as larger scallops are less vulnerable to predation. Scallop escape responses rely on anaerobic adenosine triphosphate (ATP) generation. Phosphoarginine is the source of $70 \%$ of the ATP used during swimming (Livingstone et al. 1981, Chih \& Ellington 1983, Gade 1983, Bailey et al. 2003). Anaerobic glycolysis terminates the escape response and supports recuperation during valve closure (Livingstone et al. 1981, Ellington 1983). Aerobic metabolism is required for full recuperation of initial phosphoarginine levels, with oxygen uptake rising significantly after exhausting exercise (Mackay \& Shumway 1980, Thompson et al. 1980, Tremblay et al. 2006, Kraffe et al. 2008). The scallop escape response is metabolically similar to sprint swimming by fish. Much as the power requirements of sprint swimming seem to explain the positive allometry of muscle glycolytic capacities in pelagic fish, the increases in drag with size could favour increases in the adductor muscle's capacity for anaerobic metabolism.

The increasing importance of reproduction with size may influence the size dependence of other functional traits in a broadcast-spawning organism such as Placopecten magellanicus. As P. magellanicus begin to have gonads at $25 \mathrm{~mm}$ and as the relative gonad size increases as scallops grow, size-related changes in physiological characteristics could reflect the increasing importance of reproduction. However, in all scallops studied to date, including $P$. magellanicus, initial escape performance is affected less by reproductive investment than repeat performance (Brokordt et al. 2000a,b, 2006, Kraffe et al. 2008).

The present study examined the impact of size on the use of the adductor muscle during escape responses and on muscle metabolic capacities in Placopecten magellanicus. To this end, we characterized: (1) force production during escape responses, (2) the activity of enzymes of energy metabolism and (3) phosphoarginine content of the adductor muscle, for individuals ranging from 30 to $100 \mathrm{~mm} \mathrm{SH}$, the size range of greatest mobility. By examining the size dependence of escape performance and related biochemical components, we sought to evaluate whether changes in swimming activity through ontogeny are linked to patterns of muscle use and to the metabolic capacities of the adductor muscle.

\section{MATERIALS AND METHODS}

Scallop holding conditions. For measurements of escape response performance, cultured Placopecten magellanicus ranging from $\sim 35$ to $100 \mathrm{~mm}$ SH were obtained from Pétoncles 2000 (Cap-aux-Meules, Îlesde-la-Madeleine, Québec, Canada) in September and October 2004. For measurement of biochemical parameters, scallops ranging from 30 to $93 \mathrm{~mm}$ were obtained from CultiMer (Cap-aux-Meules) in September 2008. These 3 samples, each of 29 scallops, had similar ranges of shell dimensions and soft tissue masses, except that gonad masses and the gonadosomatic index had a wider range in September 2004, presumably because spawning had not finished (Table 1).

These scallops had been held in House Harbour lagoon after their collection as spat, and were then 


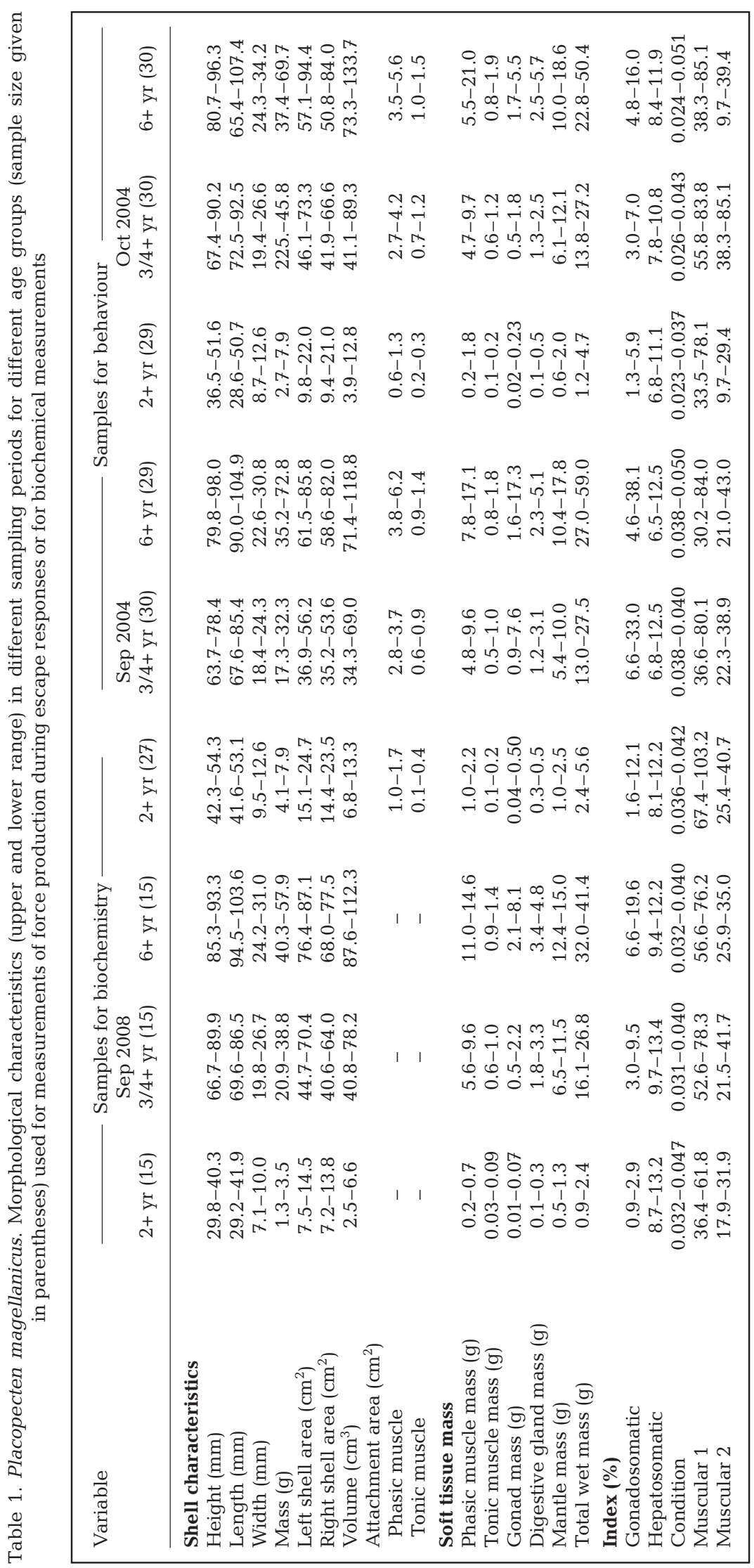

grown for a year in the open ocean east of the Îles-de-la-Madeleine (New Hall area). Subsequently, juvenile scallops were transferred to pearl nets for intermediate culture, and their densities were progressively reduced to maintain optimal growth. To cover the target size range, we used scallops of different ages; the shell heights of 2+ scallops ranged from 30 to $54 \mathrm{~mm}$, whereas those of older scallops ranged from 64 to $98 \mathrm{~mm}$ (Table 1). Approximately a week before the experiments, the scallops were brought to the Ministère de l'Agriculture des Pêcheries et de l'Alimentation du Québec's wet laboratory at House Harbour and held in running seawater pumped from the lagoon $\left(10\right.$ to $12^{\circ} \mathrm{C}$; salinity $\sim 30 \%$ o). The scallops were given a week to recuperate from transportation and to become accustomed to laboratory conditions.

Force measurements. Force production during escape responses was measured according to Fleury et al. (2005), as modified by Guderley et al. (2008). In this approach, the scallop's lower valve is attached to the bottom of an aquarium, and the lever of a force gauge is placed under the upper valve, which is free to move. Rapid increases in force production reflect contractions of the phasic muscle, whereas sustained force production is due to the tonic muscle. Scallops were transported individually to the experimental tanks and kept in circulating seawater (September: 10 to $16^{\circ} \mathrm{C}_{i}$ October: 8 to $13^{\circ} \mathrm{C}_{i} \sim 30 \%$ salinity) during the force measurements. The lever of the force gauge separated the valves by the distance observed for normally ventilating scallops of their size. The scallops were stimulated to react by stroking the mantle with an arm of their starfish predator Asterias vulgaris. This test lasted $10 \mathrm{~min}$.

After the measurements, shell dimensions were taken ( $\mathrm{SH}$, length and width). The scallops were dissected to obtain the mass of the shell, muscle, gonad, digestive gland and remaining tissues (mantle mass). The valves were photographed to measure the attachment area of the phasic and tonic adductor muscles by image analysis (Image Pro, Media Cybernetics). 
Sampling for biochemical parameters. For the enzyme and protein assays, 45 scallops were dissected to obtain the anatomic data noted above. The adductor muscle of each scallop was immediately frozen at $-80^{\circ} \mathrm{C}$. For phosphoarginine determination, the adductor muscle of 45 other scallops, distributed throughout the desired size range, was rapidly removed, freeze-clamped in liquid nitrogen and stored at $-80^{\circ} \mathrm{C}$ (removal and freezing of the muscle was completed in $10 \mathrm{~s})$. All samples were kept on dry ice during transfer to Université Laval where they were stored at $-80^{\circ} \mathrm{C}$ until biochemical analysis (3 mo for enzyme activities, 6 mo for phosphoarginine measurements).

Escape response analysis. Within the $10 \mathrm{~min}$ test period, the duration of the escape response was determined as the time of the last phasic contraction preceding a minute of continuous tonic contraction. Phasic contractions (claps) were described by their total number, number during the escape response and number in the first series, time of first and last clap, time to initiate the first phasic series, contractile frequency during the first series and during the escape response, and minimal interval between 2 phasic contractions. Tonic contractions were described according to their number and the percentage of time spent in tonic contraction during the tests. Scallops that show a high number of tonic contractions generally intersperse these contractions between series of claps (Fleury et al. 2005). Maximal and mean forces of phasic contractions and maximal force of tonic contractions were determined. Force production during phasic and tonic contractions was expressed relative to the insertion area of phasic and tonic muscles, respectively $\left(\mathrm{N} \mathrm{mm}^{-2}\right)$.

Enzyme assays. Adductor muscle samples were homogenised on ice using a minimasher (Tremblay et al. 2006) in 9 vol of $50 \mathrm{mM}$ imidazole-HCl, $2 \mathrm{mM}$ EDTA-Na $5 \mathrm{mM}$ EGTA, $1 \mathrm{mM}$ dithiothreitol, $0.1 \%$ Triton X-100 and $20 \mathrm{mM} \mathrm{NaF}$ (only for phosphofructokinase $[\mathrm{PFK}]), \mathrm{pH}$ 6.6. The homogenates were centrifuged (IEC MicroMax) at $4^{\circ} \mathrm{C}$ for $10 \mathrm{~min}$ at $2462 \mathrm{~g}$. Enzyme activity was measured at $18^{\circ} \mathrm{C}$ using a microplate spectrophotometer (SPECTRAmax 190, Molecular Devices) by following absorbance changes of $\mathrm{NAD}(\mathrm{P}) \mathrm{H}$ at $340 \mathrm{~nm}$, with the exception of citrate synthase, which was monitored at $412 \mathrm{~nm}$ to detect the transfer of sulphydryl groups from Coenzyme A to 5,5'-dithiobis(2-nitrobenzoic acid). All the tests were performed in triplicate. Specific activity was expressed in international units ( $\mu$ mole of substrate converted to product per minute) per gram of muscle wet mass. We followed the assay conditions given by Brokordt et al. (2000a), except that: (1) for PFK (EC 2.7.1.11), fructose2,6-diphosphate was omitted and (2) for octopine dehydrogenase $\left(\mathrm{ODH}_{;} \mathrm{EC}\right.$ 1.5.1.11), we included a control in which L-arginine (1.5 mM) was omitted.

Phosphoarginine determination. Phosphoarginine concentration was determined following Viant et al. (2001) using high-performance liquid chromatography (HPLC). This method employed a reversed-phase amino column (Luna $\mathrm{NH}_{2} 5 \mu 100 \AA, 250 \times 4.6 \mathrm{~mm}$ and $\mathrm{NH}_{2}$ Security Guard Cartridge, $4 \times 3 \mathrm{~mm}$; both Phenomenex) and a $\mathrm{KH}_{2} \mathrm{PO}_{4}$ buffer (20 mM, pH 2.6)-acetonitrile (72:28) isocratic mobile phase. Solvents were filtered through a $0.2 \mu \mathrm{m}$ membrane filter, degassed with helium, and used at a flow rate of $1 \mathrm{ml} \mathrm{min} \mathrm{m}^{-1}$. A standard curve of phosphoarginine (between 0.001 and $4 \mathrm{mM}$ ) was used to facilitate peak identification and quantification.

Calculations. Different indices were used to assess scallop status (Table 2): the gonadosomatic index (GSI; gonad mass as percentage of total soft tissue mass), the hepatosomatic index (digestive gland mass as percentage of total soft tissue mass), Muscular Indices 1 (total muscle mass as percentage of total soft tissue mass muscle mass) and 2 (total muscle mass as percentage of shell mass) and a condition index reflecting the proportion of the volume between the valves filled by the soft tissues. The latter was calculated according to Lafrance et al. (2003), i.e.:

$$
\begin{aligned}
& \text { Condition index }=\frac{\text { total soft tissue mass }}{\text { shell volume }} \times 100 \\
& \text { Shell volume }=\pi \times\left(\frac{\text { height }}{2}\right) \times\left(\frac{\text { length }}{2}\right) \times\left(\frac{\text { width }}{2}\right)
\end{aligned}
$$

Table 2. Placopecten magellanicus. Range of values for escape response characteristics in 2 sampling periods (sample size given in parentheses), used in principal components analyses

\begin{tabular}{|lcc|}
\hline Variable & $\begin{array}{c}\text { Sep 2004 } \\
(86)\end{array}$ & $\begin{array}{c}\text { Oct 2004 } \\
(89)\end{array}$ \\
\hline Number of phasic contractions & $15-58$ & $6-70$ \\
Number of phasic contractions during escape & $15-54$ & $6-64$ \\
Frequency of phasic contractions during & $7.1-44.9$ & $3.8-179.9$ \\
escape (claps min $^{-1}$ ) & & \\
Number of phasic contractions in first series & $2-37$ & $1-44$ \\
Frequency of phasic contractions in first & $0.3-2.4$ & $0.3-1.9$ \\
series (claps s ${ }^{-1}$ ) & & \\
Number of tonic contractions & $2-12$ & $1-12$ \\
Duration of tonic contractions $(\%)$ & $40-96$ & $40-99$ \\
Maximal phasic contraction force $\left(\mathrm{N} \mathrm{cm}^{-2}\right)$ & $2.8-6.9$ & $1.7-6.9$ \\
Mean phasic contraction force $\left(\mathrm{N} \mathrm{cm}^{-2}\right)$ & $1.7-4.7$ & $1.1-5.1$ \\
Maximal tonic contraction force $\left(\mathrm{N} \mathrm{cm}^{-2}\right)$ & $6.2-31.4$ & $5.1-17.0$ \\
Escape duration (s) & $38.8-320$ & $8.7-397.9$ \\
First clap time (s) & $0-19.9$ & $0.1-30.6$ \\
Last clap time (s) & $68-596$ & $17.7-596.0$ \\
Minimum interval between 2 claps (s) & $0.1-1.9$ & $0.2-2.0$ \\
Beginning of first series (s) & $0-31.3$ & $0.1-186.7$ \\
\hline
\end{tabular}


As the proportions of scallops may change as a function of size, the constant $(c)$ was determined for the 3 size groups by modifying the formula for the volume of a cylinder with the empirically estimated constant assessed from the water displaced by a clay model of the space between valves of known dimensions $(0.50$ for 36 to $52 \mathrm{~mm}$ scallops; 0.55 for 67 to $82 \mathrm{~mm}$ scallops; 0.52 for 84 to $96 \mathrm{~mm}$ scallops).

Statistical analysis. $\mathrm{SH}$ is the characteristic typically used to assess size dependence of functional properties in scallops (Caddy 1968, 1972, Dadswell \& Weihs 1990). To ascertain that SH reliably translates the variability of the overall morphology of the scallops in our samples, the morphological traits of the scallops used for the escape response tests (September and October) and for biochemical characterisation (Table 1) were submitted to principal components analysis (PCA). The first principal component accounted for 94, 95 and $96 \%$ of the variance in the 3 analyses. For these samples, the morphological characteristics, including $\mathrm{SH}$, contributed with similar weights (Fig. 1) to this first principal component. To facilitate comparisons with other studies of scallop performance, we retained $\mathrm{SH}$ to indicate scallop size.

The force recordings of escape response performance yield many variables (or descriptors), increasing the risk of erroneous identification of significant relationships. Thus, a PCA was performed to create new combined variates (i.e. random variables; Legendre \& Legendre 1998) and, thus, to simplify the analysis of size on these behaviours. PCA quantifies the role of the original descriptors in the formation of the new variates. These variates were named (and interpreted) according to the original descriptors that had loadings $\geq 0.30$ (Tabachnick \& Fidell 1989). Individual scores for these variates were calculated, and their size dependence was examined using quadratic regression analysis. Then, to examine whether the individual descriptors (behaviours), which strongly influenced the variates with significant size dependence, were themselves influenced by size, we used regression (linear or quadratic) analyses or robust regression analyses. Size dependence of biochemical parameters was examined in the same fashion. Scores, individual behaviours and biochemical parameters $(x)$ were centred on their mean before computing the regressions to reduce the linear dependence of $x^{2}$ on $x$ (Legendre \& Legendre 1998). Robust regression was used when the assumed model deviated slightly from expectations of parametric statistics (Gaussian law), as well as to limit the effect of outliers in data sets (Legendre \& Legendre 1998, Scherrer 2009).

To determine how reproductive investment affected escape response behaviours and muscle properties, we first examined the size dependence of the GSI using regression (linear or quadratic) analysis. Then, the impact of GSI on the scores of the behavioural parameters and on the enzymatic activities was examined using regression (linear or quadratic) analyses, with the index as the independent variable. Again, robust regression was used when the assumed model deviated from expectations of parametric statistics (Gaussian law) and to limit the effect of outliers in data sets (Legendre \& Legendre 1998, Scherrer 2009).

Model selection. To decide whether quadratic regression models provided a better fit than linear regressions, the significance of the increase in $\mathrm{R}^{2}$ was tested using the following equation:

$$
F_{\text {statistic }}=d f_{j} \times \frac{R_{j}^{2}-R_{i}^{2}}{1-R_{j}^{2}}
$$

where $\mathrm{R}_{i}^{2}$ is the $\mathrm{R}^{2}$ for the $i$ th order, and $\mathrm{R}_{j}^{2}$ is the $\mathrm{R}^{2}$ for the next higher order, and $\mathrm{df}_{j}$ is the degrees of freedom for the higher-order equation. The degrees of freedom in the numerator are $j$, while $\mathrm{df}_{j}=n-j-1$ is the degrees of freedom in the denominator (Zar 1974).

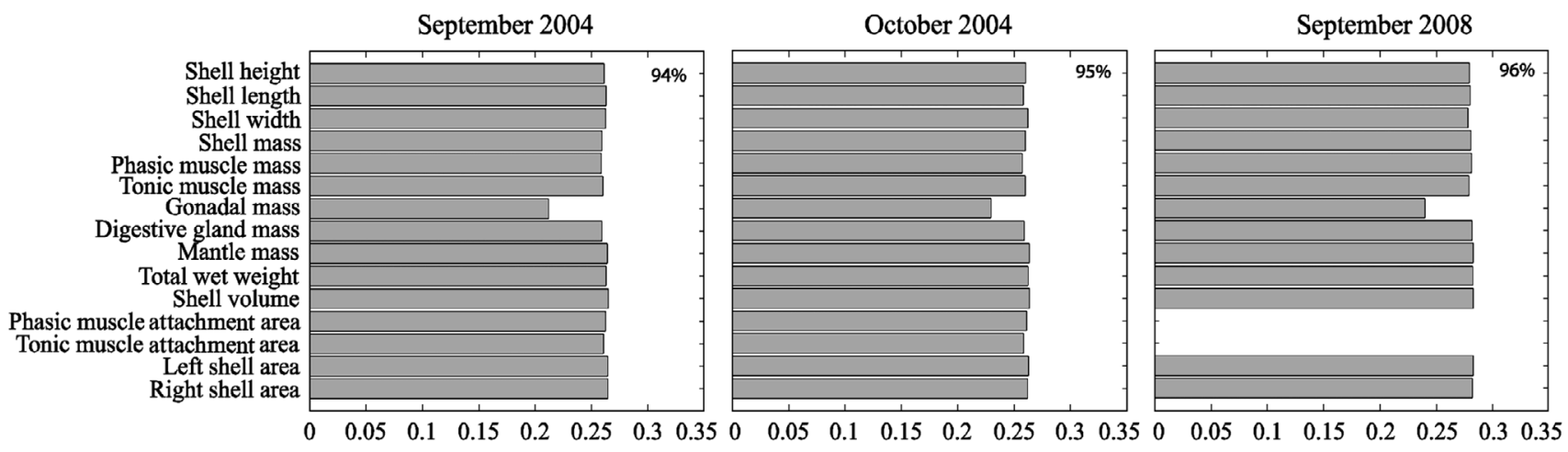

Fig. 1. Placopecten magellanicus. Weights of original descriptors, for the first principal component, in the linear combinations from which individual scores were computed from morphological parameters. Phasic and tonic muscle insertions were not measured on the scallops used for biochemical analysis. Percentages indicate the proportion of variance explained by the components 


\section{RESULTS}

\section{Escape responses}

The range of values for escape response behaviours obtained from the force recordings was similar in September and October (Table 2). The first 3 principal components (PC) of the PCA carried out on these variables accounted for 24,19 and $13 \%$ of the variance in September and for 27, 16 and $14 \%$ in October. The 3 PCs were structured in a similar fashion in both months (Fig. 2). The first PC was influenced by the number of phasic and tonic contractions, as well as by escape duration. The loadings on the second PC varied more between September and October, with the number of phasic contractions having high loadings in September, but not October. In October, the second PC was most strongly influenced by the minimum interval between 2 claps. In both months, the third PC was primarily influenced by phasic and tonic force production.

We analysed the allometry of escape response behaviour in 2 steps. (1) We used regression analysis to examine the size dependence of scores from the PCs. (2) We examined whether the primary behaviours upon which these PCA variates were based showed a similar allometry. We named the PCA variates according to the major escape response characteristics by which they were influenced (Fig. 2). In September, the first PC was dominated by parameters linked to endurance, the second by numbers of phasic contractions and the third by phasic force development. In October, the first PC was influenced most by numbers of phasic contractions, the second by the frequency of contractions and the third by phasic force development.

In both months, the first and third variates showed a significant relationship with size (Fig. $3)$, whereas the second did not. For September, the size dependence of both the variates 'endurance' and 'phasic forces' was quadratic, with the regression for phasic forces stabilizing at greater size (Fig. 3). The quadratic regressions explained the data significantly better than linear models, but, generally, both models were significant $(p<0.05)$. For October, the first and third PCs 'number of phasic contractions' and 'phasic forces' showed quadratic size dependence, again first increasing and then decreasing with size (Fig. 3). While these
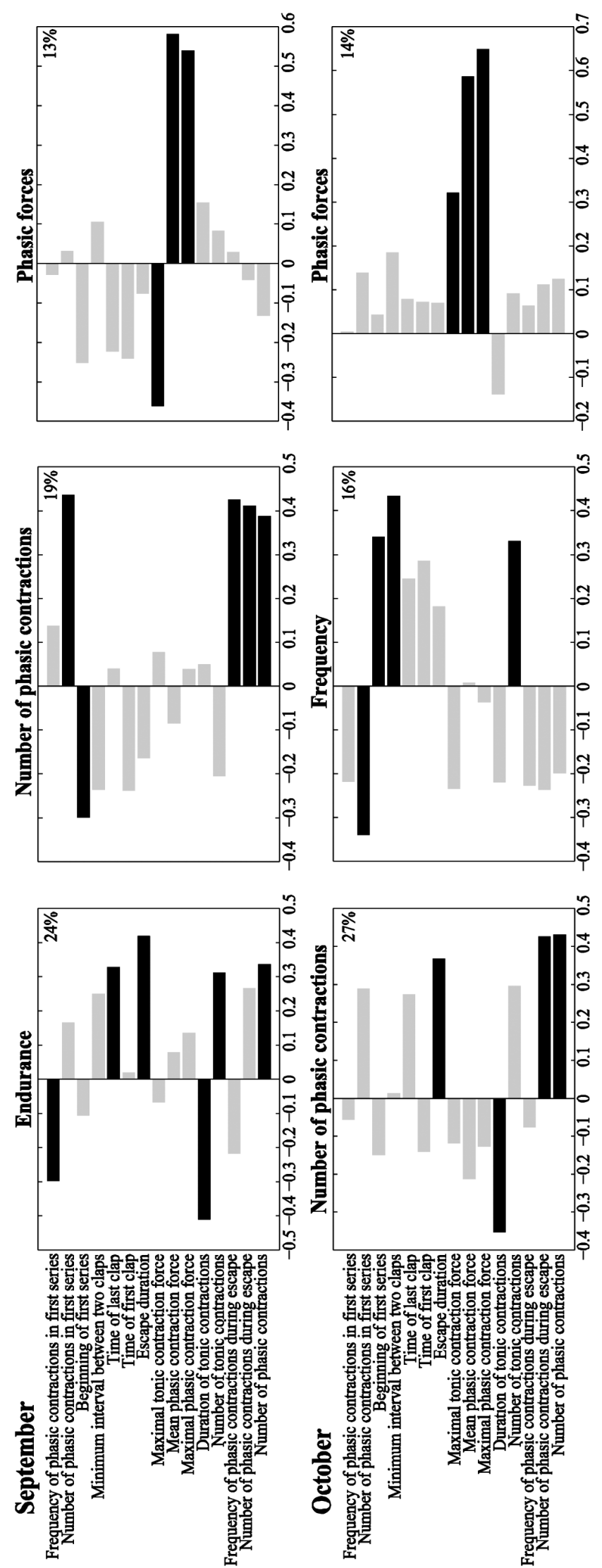
similar allometric patterns suggest that escape response performance is best in scallops of intermediate size, these regression models explain at most $37 \%$ of the variability in the data.

The behaviours having the greatest influence upon the first and third principal components also varied with size. In September, the time of the last clap, the number of tonic contractions and the frequency of contractions in the first series were significantly influenced by size, with the latter 2 having a quadratic size dependence (Table 3$)$. In October, but not in September $\left(\mathrm{R}^{2}=\right.$

\section{September}
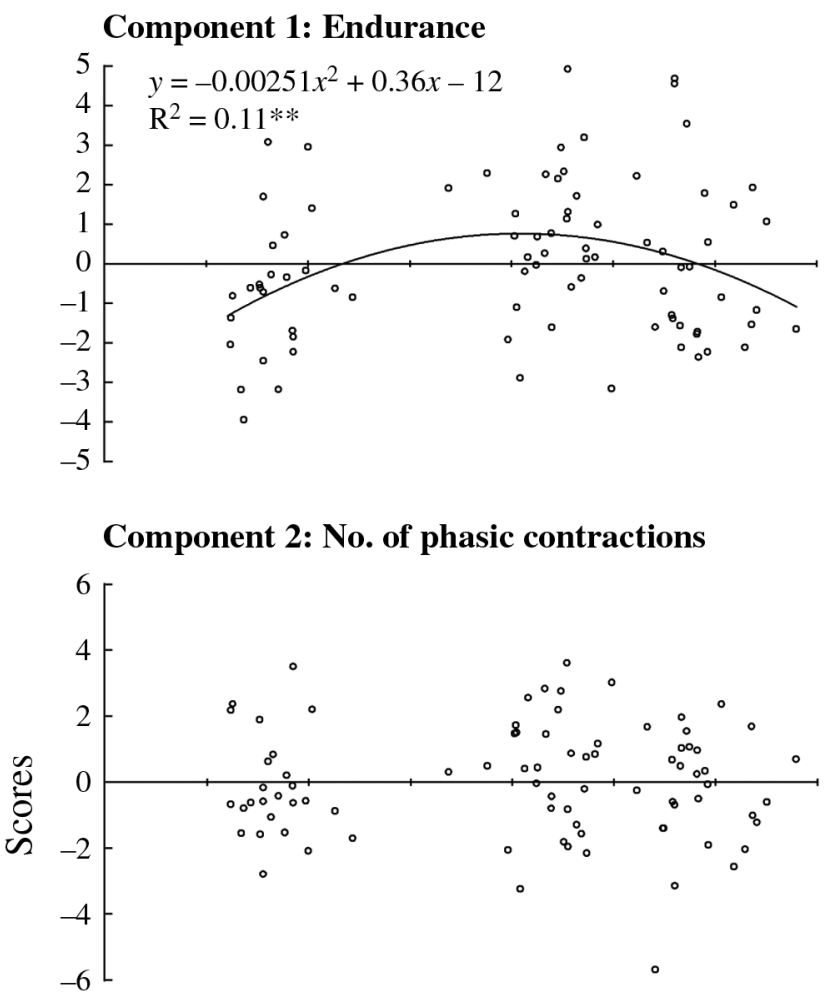

Component 3: Phasic forces

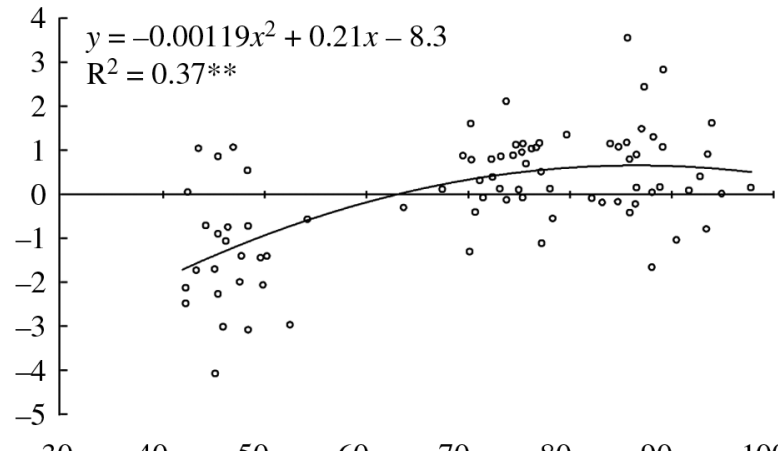

0.06; $p=0.08$ ), the number of phasic contractions showed the same allometry as the first principal component (Table 3). In both September and October, mean phasic force $\left(\mathrm{N} \mathrm{cm}^{-2}\right)$ increased linearly with size (Fig. 4). Maximal phasic force $\left(\mathrm{N} \mathrm{mm}^{-2}\right)$ rose with size and then declined (Fig. 4). Maximal tonic force decreased in a linear fashion with size in September, but not in October (Fig. 4). Although these regressions explained at most $35 \%$ of the variability in the data, this size dependence is consistent with the allometry of the scores from the PCA.

\section{October}

\section{Component 1: No. of phasic contractions}

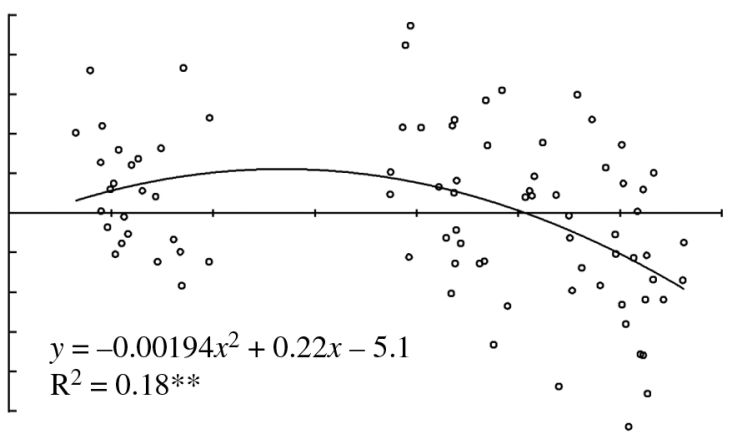

\section{Component 2: Frequency}

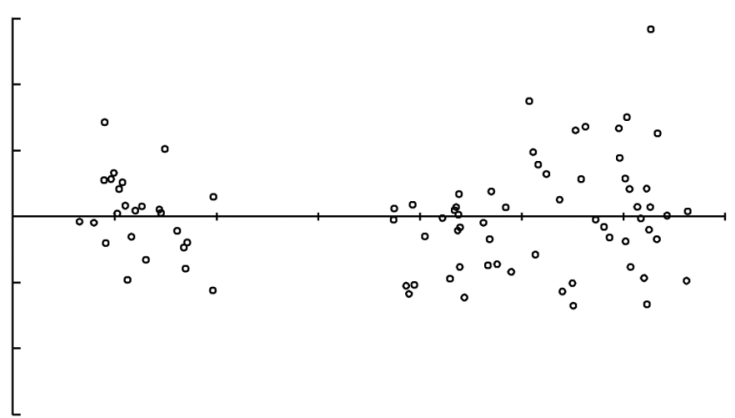

\section{Component 3: Phasic forces}

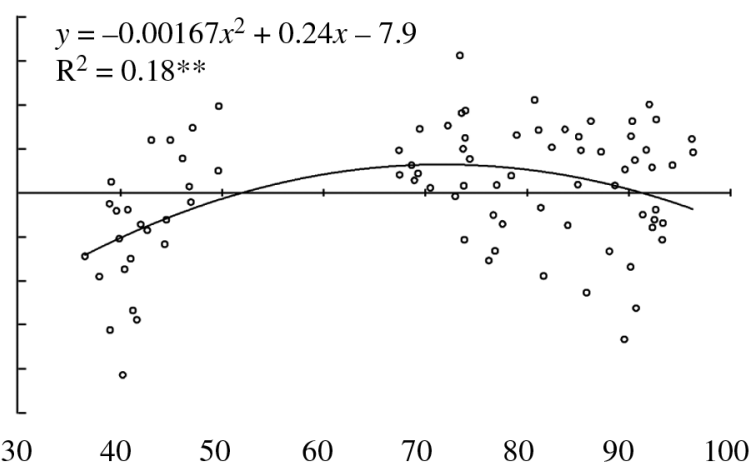

Shell height (mm)

Fig. 3. Placopecten magellanicus. Relation between individual scores and shell height (mm) for the first 3 components in

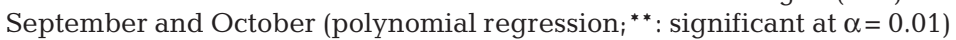




\section{Metabolic support of escape responses: enzyme activities and phosphoarginine levels}

The size dependence of enzyme activities in the adductor muscle of Placopecten magellanicus differed according to the metabolic pathway in which the enzymes function. Enzymes from anaerobic glycolysis (PFK and $\mathrm{ODH}$ ) followed a quadratic relation with size (Fig. 5). PFK activity declined at a slightly greater $\mathrm{SH}$ than $\mathrm{ODH}$ activities. In contrast, arginine kinase (AK) showed no significant effect of
Table 3. Placopecten magellanicus. Significant relations between escape response behaviours (with strong loadings on the first principal component) and shell height $(\mathrm{SH}, \mathrm{mm})$ in September and October. Polynomial and linear regressions provided the best fit

\begin{tabular}{|lccc|}
\hline Variable & SH dependence & $\mathrm{R}^{2}$ & $\mathrm{p}$ \\
\hline September & $-2.33 x+465.53$ & 0.05 & 0.04 \\
Time of last clap & $-0.0002 x^{2}+0.28 x-4.51$ & 0.11 & 0.009 \\
Number of tonic contractions & $0.0003 x^{2}-0.05 x+2.64$ & 0.14 & 0.003 \\
$\begin{array}{l}\text { Frequency of phasic contractions } \\
\text { during first series }\end{array}$ & & & \\
October & $-0.02 x^{2}+1.97 x-12.42$ & 0.27 & 0.0002 \\
Number of phasic contractions & $-0.01 x^{2}+1.70 x-14.94$ & 0.14 & 0.0004 \\
$\begin{array}{l}\text { Number of phasic contractions } \\
\text { during escape }\end{array}$ & $0.15 x+65.73$ & 0.05 & 0.04 \\
Duration of tonic contractions $(\%)$ & & & \\
\hline
\end{tabular}
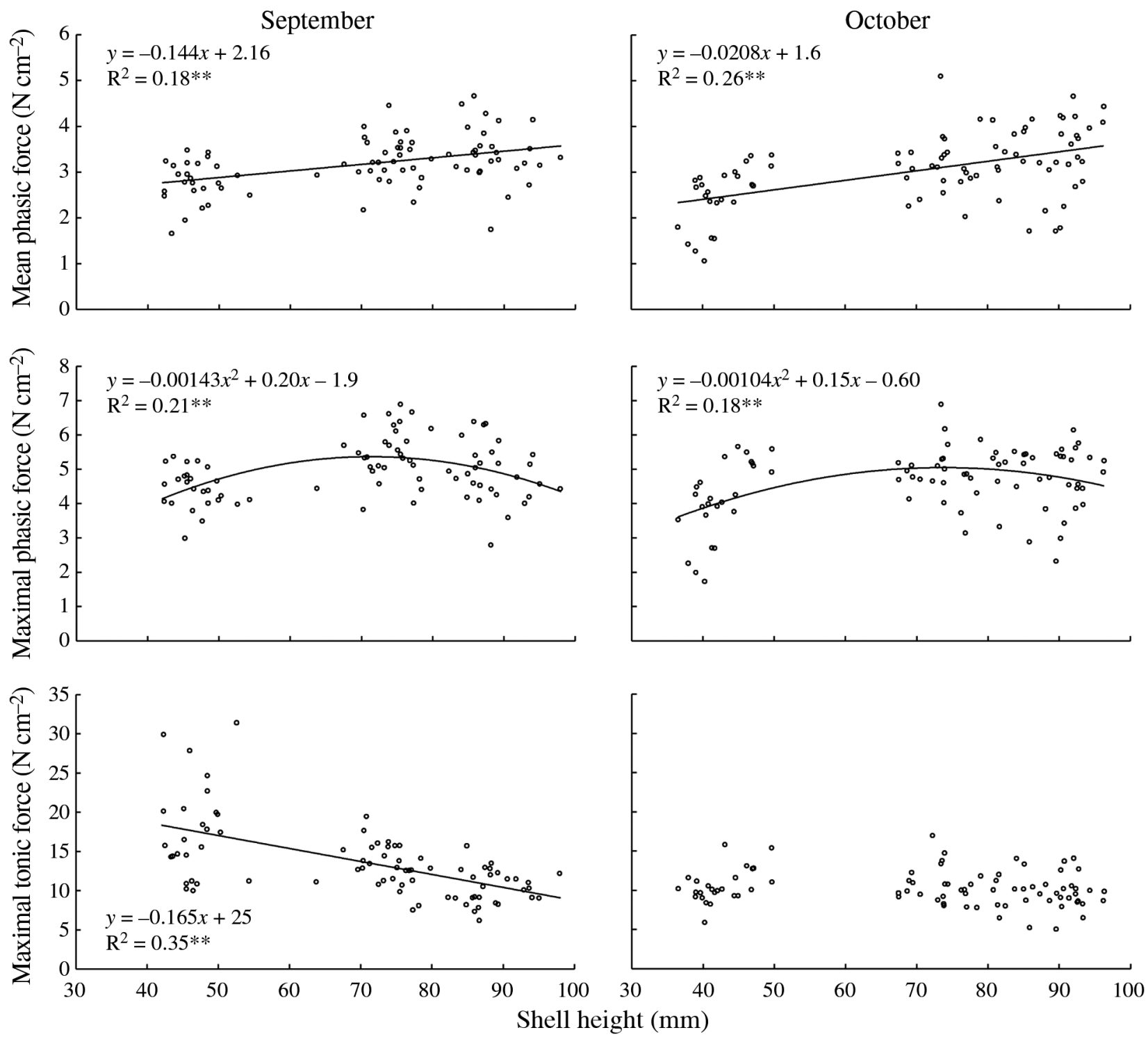

Fig. 4. Placopecten magellanicus. Relation between the observed behaviours and shell height (mm) for September and October. Polynomial and linear regression provided the best fit $\left({ }^{* *}\right.$ : significant at $\left.\alpha=0.01\right)$ 
size $\left(\mathrm{R}^{2}=0.15 ; \mathrm{p}=0.09\right.$; Fig. 5). The activity of citrate synthase (CS), a mitochondrial enzyme, decreased with an increase in scallop size (Fig. 5). Phosphoarginine contents changed with size in a fashion similar to that of PFK and ODH (Fig. 5).

\section{Impact of reproductive investment}

In both September and October, the GSI rose with increasing size (Fig. 6), following a quadratic relationship in September and a linear one in October. The range of GSI values was twice as great in September as in October. We analysed the impact of reproductive investment on escape response performance using regression analyses between GSI and PCA scores. The third principal component showed a quadratic relation to GSI in September, while in October, the first and
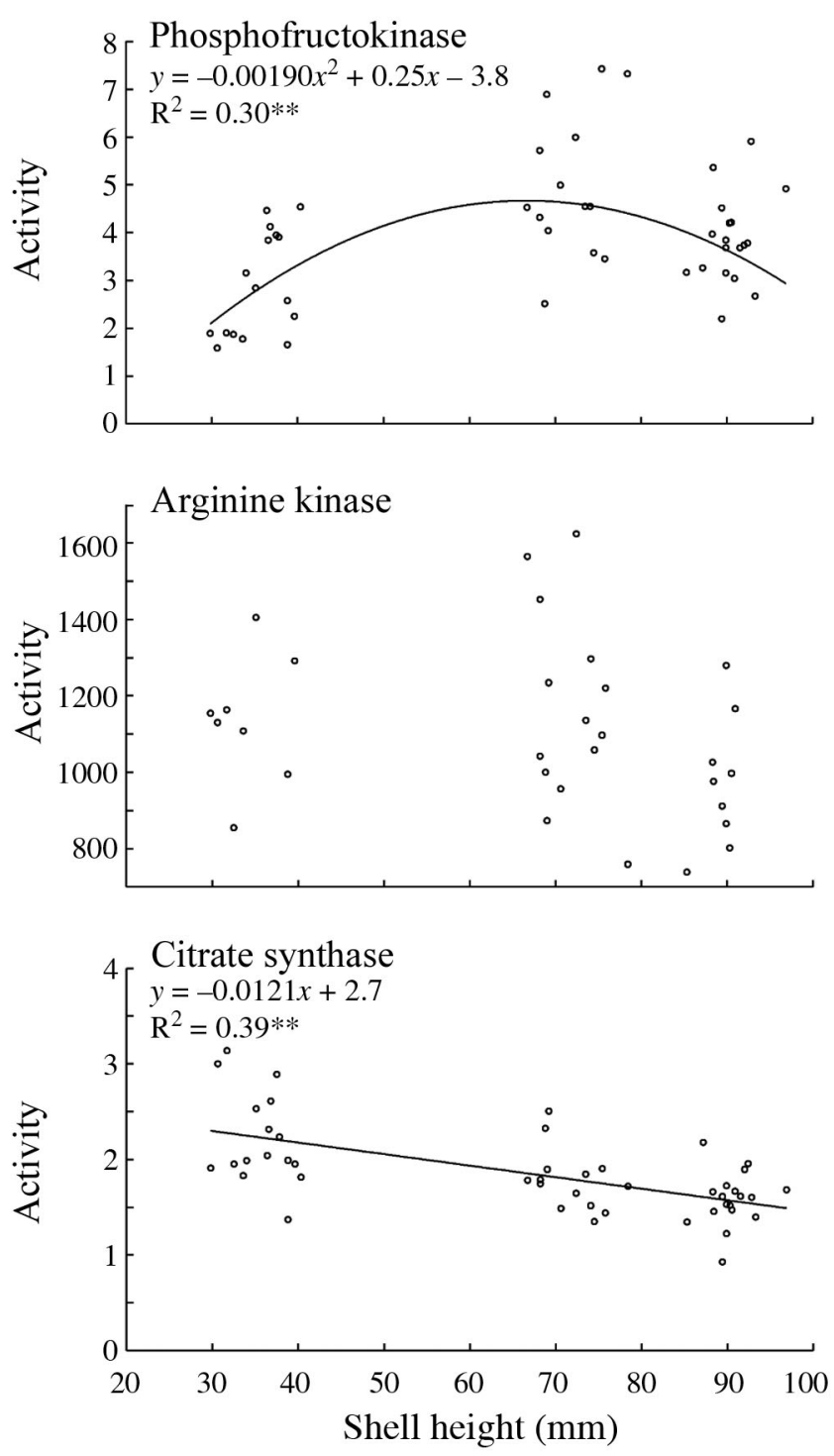

third PCs showed a quadratic relation. The second principal component showed no relation to GSI in both months (Table 4). In both months, a quadratic relation was observed between GSI and the scores of the third variate (Table 4 ).

We next examined whether the primary behaviours upon which the variates were based changed with GSI (Table 4). In October, half of the variables associated with the first 2 components changed with GSI, but not always following the same pattern as the calculated scores (Table 4). For both months, all the variables associated with the third component (except 'maximal tonic force' in October) showed similar and relatively strong dependence on GSI (Table 4, Fig. 6). However, GSI did not influence muscle levels of PFK, ODH, or $\mathrm{AK}$, although $\mathrm{CS}$ activity decreased with GSI $\left(\mathrm{R}^{2}=\right.$ $0.28 ; \mathrm{p}=0.0002$; data not shown), presumably reflecting an impact of size on both parameters.
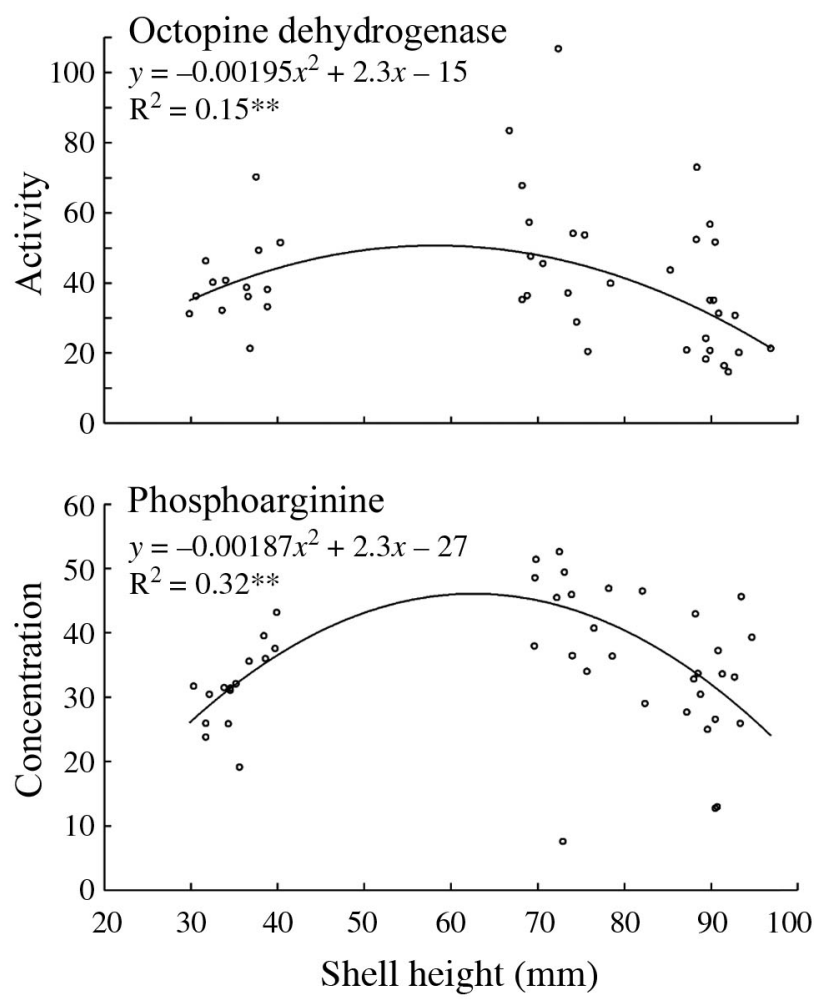

Fig. 5. Placopecten magellanicus. Relationships between shell height and enzymatic activity ( $\mathrm{U} \mathrm{g}^{-1}$ wet mass) or phosphoarginine concentration ( $\mu \mathrm{mol} \mathrm{g}^{-1}$ wet mass) in phasic adductor muscle. Polynomial regressions (except for citrate synthase) provided the best fit $\left({ }^{* *}\right.$ : significant at $\alpha=0.01$ ) 


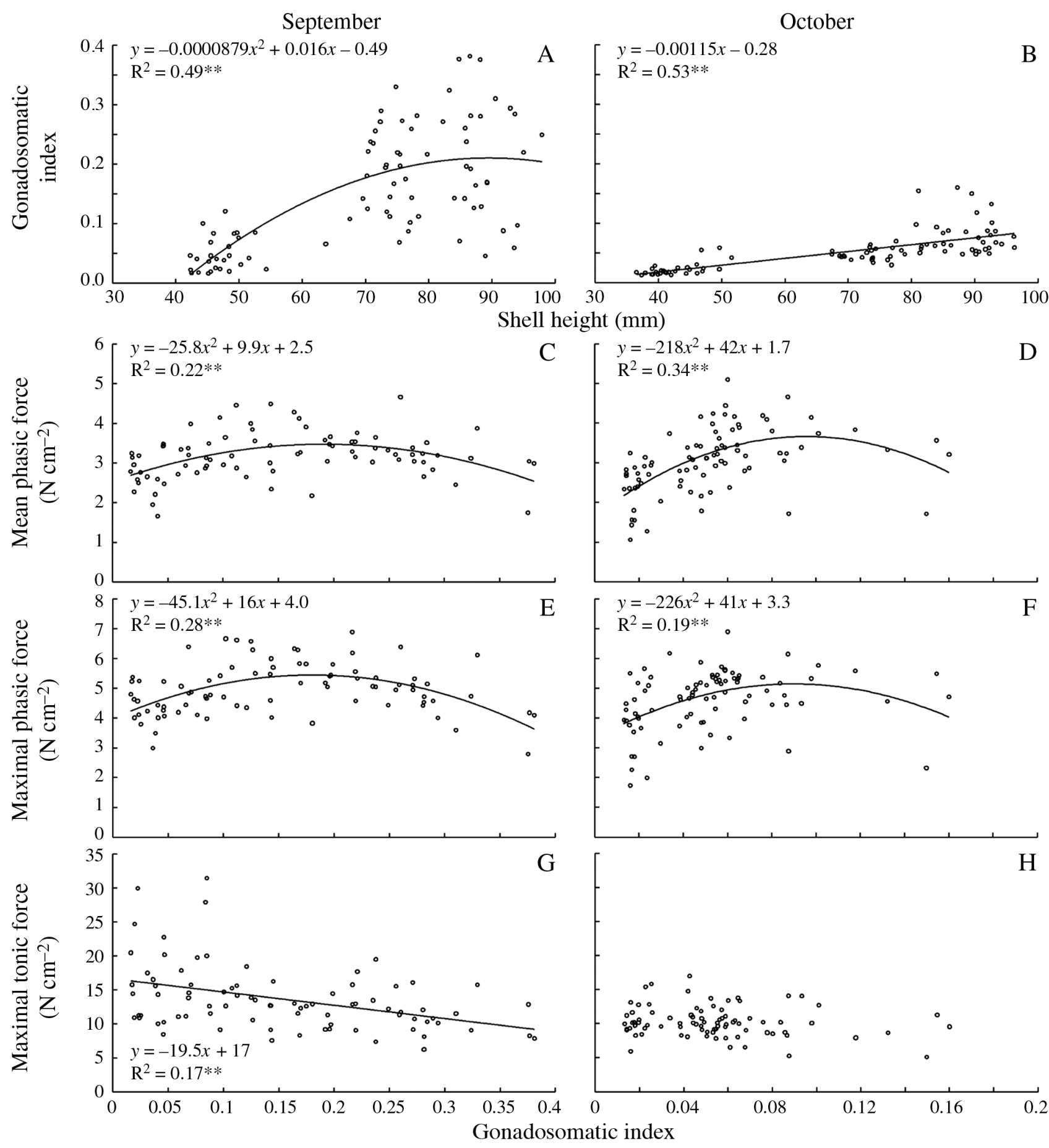

Fig. 6. Placopecten magellanicus. Relationships between (A, B) gonadosomatic index and shell height (mm) and (C to H) observed behaviour (related to the third principal component) and gonadosomatic index. We show the linear or polynomial regressions that provided the best fit ${ }^{* *}$ : significant at $\left.\alpha=0.01\right)$

\section{DISCUSSION}

During ontogeny, the mobility and swimming style of Placopecten magellanicus change markedly, with scallops using byssal attachment to maintain position at small sizes $(<30 \mathrm{~mm})$ and progressively becoming more mobile as they grow (Caddy 1968, 1972). Once the size of peak hydrodynamic efficiency is passed, given the larger shell size and perhaps a certain resistance to predation, swimming performance decreases. P. magellanicus of intermediate size (40 to $80 \mathrm{~mm}$ ) are the fastest swimmers (Dadswell \& Weihs 1990). In parallel with 
Table 4. Placopecten magellanicus. Relation between observed behaviours and the gonadosomatic index (GSI) for the principal components (PC) that show significant relationship to GSI. Polynomial and linear regressions provided the best fit

\begin{tabular}{|lccc|}
\hline Variates or Variables & GSI dependence & $\mathrm{R}^{2}$ & $\mathrm{p}$ \\
\hline September, PC3 & & & \\
Scores & $-55.91 x^{2}+23.66 x-1.77$ & $0.26<0.0001$ \\
Maximal phasic force & $-45.08 x^{2}+16.25 x+3.98$ & $0.28<0.0001$ \\
Mean phasic force & $-25.81 x^{2}+9.85 x+2.53$ & $0.22<0.0001$ \\
Maximal tonic force & $-19.52 x+16.64$ & 0.17 & 0.0001 \\
October, PC1 & & & \\
Scores & $309.08 x^{2}-57.75 x+1.88$ & 0.101 & 0.0134 \\
Number of phasic contractions & $-84.61 x+44.25$ & 0.05 & 0.0423 \\
Duration of tonic & $-2070.61 x^{2}+32.57 x+67.51$ & 0.08 & 0.0268 \\
$\quad$ contractions $(\%)$ & & & \\
October, PC3 & & & \\
Scores & $-274.39 x^{2}+50.84 x-1.65$ & 0.15 & 0.0013 \\
Maximal phasic force & $-226.35 x^{2}+40.70 x+3.32$ & 0.19 & 0.0002 \\
\hline
\end{tabular}

allometric changes in swimming strategy, muscle use during escape responses and muscle metabolic capacities changed with size in $P$. magellanicus. The size at which these parameters peaked lay near the centre of the size range examined. In fact, the transition size was similar for these functional parameters, with biochemical characteristics peaking near $60 \mathrm{~mm}$, whereas escape response parameters peaked near $70 \mathrm{~mm}$.

Allometric changes in the use and metabolic capacities of muscle may facilitate swimming, much as has been suggested for morphological traits of Placopecten magellanicus (Gould 1971, Thayer 1972). Two of the 3 principal components that encapsulated the variability of the escape response were significantly related to size. The number of phasic contractions showed a significant size dependence in October, but not in September. While maximal phasic force peaked at intermediate sizes, mean phasic force increased as a direct function of $\mathrm{SH}$. Increased phasic force in larger scallops should enhance the ejection of water and help compensate for the greater shell mass and drag experienced at higher speeds by large scallops. The importance of overcoming drag has been used to explain the spacing of riblets on the shells of $P$. magellanicus (Anderson et al. 1997). At $\mathrm{SH}>40 \mathrm{~mm}$, riblet spacing falls to the optimal size for drag reduction at physiological swimming speeds. Changes in swimming requirements with size may also have influenced escape response behaviour.

The size dependence of muscle performance was mirrored in the biochemical support of muscle activity. The ATP used by phasic muscle during swimming is mainly derived from phosphoarginine (Zwaan et al. 1980, Chih \& Ellington 1983, Gade 1983), with anaerobic glycolysis providing the remainder. Phosphoarginine levels and PFK and ODH activities changed in parallel with the size dependence of escape response performance. The parallel allometry suggests that these biochemical characteristics are linked with escape response requirements. In pelagic fish, positive allometry of muscle glycolytic capacities has been related to power requirements of sprint swimming. In $P$. magellanicus, we found a parallel size dependence of maximal phasic force production (per attachment area), muscle glycolytic capacity and phosphoarginine contents. Hydrodynamic constraints seem to have influenced muscle metabolic capacities in scallops and fish.

Reproductive investment becomes increasingly important as scallops become larger. By reducing aerobic scope and muscle metabolic capacities, reproductive investment slows the recuperation of scallops from exhaustive escape responses (Brokordt et al. 2000a,b, Kraffe et al. 2008). Our proxy for reproductive investment, GSI, was significantly linked with phasic and tonic force production. However, in September, when GSI showed a greater range, GSI affected fewer behaviours than in October. Furthermore, muscle metabolic capacities were independent of GSI. We conclude that while reproductive investment affects aspects of escape response behaviour and can affect muscle biochemistry (Brokordt et al. 2000a,b, Kraffe et al. 2008), inter-individual differences in GSI do not explain the size dependence of escape response behaviours or of muscle metabolic capacities.

In contrast to the fairly detailed studies of the allometry of scallop morphology (Gould 1971, Thayer 1972, Soemodihardjo 1974, Dadswell \& Weihs 1990), few studies have examined the size dependence of escape response behaviours. Ours is the only study that examines the size dependence of functional characteristics such as phasic and tonic force production, contractile frequency and sensitivity. As we sought to compare individuals in a similar physiological state, we examined the scallops within the target size range (30 to $100 \mathrm{~mm}$ ) available at a given date. The rapid growth of scallops between $2+$ and $3+$ yr made it difficult to obtain scallops at 50 to $60 \mathrm{~mm} \mathrm{SH}$, but comparison of scallops sampled at different times during the year would have led to other confounding factors. Bearing this limitation in mind, we believe that within the range, 30 to $100 \mathrm{~mm}$, various escape response characteristics first increase and then decrease in Placopecten magellanicus. Comparison of data from separate studies on small and large Chlamys islandica suggests that small scallops clap more and faster, stay 
closed for less time after exhaustion and have a shorter escape response (Tremblay et al. 2006). In C. islandica, the activity of glycolytic enzymes is higher in large individuals, whereas AK is higher in small individuals (Tremblay et al. 2006). On the other hand, Schmidt et al. (2008) found no difference between the number of claps of small versus large Aequipecten opercularis. The quadratic relationship of several escape response and metabolic characteristics with the size of $P$. magellanicus brings smaller and larger individuals to have similar values. As comparison of 2 groups at opposite ends of the size distribution would have obscured such a trend, it is possible that similar relationships hold in A. opercularis.

Despite the difficulty in completely covering the target size range with Placopecten magellanicus sampled at a single point in time, we found similar inflection points for various behavioural and physiological characteristics. The size range observed for these optima lies within the range of maximal hydrodynamic efficiency observed by Dadswell \& Weihs (1990). A major role of swimming by scallops is predator avoidance. $P$. magellanicus are preyed upon by sea stars Asterias vulgaris, crabs Cancer irroratus, lobsters Homarus americanus and some species of fish (Naidu \& Meron 1986, Elner \& Jamieson 1979, Barbeau \& Scheibling 1994). Barbeau \& Scheibling's (1994) work suggests that the apparent preference of sea stars for small scallops primarily reflects the greater vulnerability of small scallops. As sea stars are slow predators, any improvement of scallop swimming capacity should decrease the probability of capture. Scallops ranging from 50 to $70 \mathrm{~mm}$ are the most effective swimmers (Dadswell \& Weihs 1990). Fairly large giant scallops may be invulnerable to crab predation, as Elner \& Jamieson (1979) observe that adult rock crabs do not feed on P. magellanicus of $>72 \mathrm{~mm} \mathrm{SH}$. In addition, the frequency and size of prey found in the stomach of American plaice Hippoglossoides platessoides led Naidu \& Meron (1986) to conclude that giant scallops are only vulnerable to fish predation $<25 \mathrm{~mm} \mathrm{SH}$. In contrast, fish predation on Chlamys islandica, a slow-growing and less active scallop species, is stronger. As well, ontogenetic changes in habitat use by $C$. islandica can be linked to susceptibility to predation by sea stars and crabs (Arsenault \& Himmelman 1996). Accordingly, small C. islandica make more phasic contractions, but remain closed for a shorter period of time after exhaustion than large scallops (Tremblay et al. 2006).

The simultaneous decline of hydrodynamic efficiency and behavioural and physiological capacities of Placopecten magellanicus $>65 \mathrm{~mm}$ may indicate that they no longer 'need' to swim, e.g. that they have reached a size refuge. As P. magellanicus continues reproducing at these and larger sizes, senescence and decreased performance following relaxation of selection pressure for reproductive success are unlikely at play. $P$. magellanicus is a long-lived species that commonly reaches sizes between 10 and $15 \mathrm{~cm}$ (Naidu \& Robert 2006). We argue that changes in predation pressure with size could affect shell morphology, swimming performance and the physiological properties of adductor muscle. Whereas these pressures would favour enhanced escape responses at smaller sizes, once a size refuge is attained, this pressure would relax, and larger individuals could become more sedentary and focus their energy on the ultimate currency of fitness, reproduction.

The increase in phasic force production with size may reflect changes in the catalytic potential of the contractile apparatus or in the biomechanical organisation of the muscle. We measured phasic force production from the sharp increases in force at the edge of the valves, not at the level of the muscle. These force values were expressed relative to the area of muscle attachment to correct for the increase in muscle size with scallop size. The catalytic capacity of myosin ATP could increase with scallop size if myofibrillar proteins account for a greater proportion of muscle in larger scallops or if the catalytic capacity of myosin ATP rises. During rapid valve closure, force measured at the edge of the valves is greater than that produced by the adductor muscle (Pérez et al. 2009), an effect best explained by analogy with a hammer, where the force applied by the hammer is considerably greater than that used to swing it. Ontogenetic changes in the muscle attachment site could change this 'amplification' of force production (Gould 1971, Soemodihardjo 1974). As the adductor muscle is positioned in an oblique fashion, increases in oblicity with size could increase its relative length, allowing greater speed of contraction, leading to a greater hammer effect during valve closure (Thayer 1972).

In summary, in Placopecten magellanicus, hydrodynamic efficiency, patterns of muscle use and muscle metabolic capacities are modified during ontogeny. Optimal morphological, behavioural and physiological traits all seem to lie in a similar size range. This supports the hypothesis that shell morphology, intrinsic muscle performance and muscle biochemistry undergo parallel allometric changes to maintain effective swimming. We suggest that the coincidence in the allometry of these morphological, behavioural and physiological properties reflects the existence of a size refuge, in which the need for escape response behaviours is reduced. P. magellanicus is less preyed upon as it reaches larger sizes (Elner \& Jamieson 1979, Naidu \& Meron 1986, Barbeau \& Scheibling 1994). The size at which predation decreases is similar to that at which locomotor performance is reduced. 
Further, as P. magellanicus grows (or gets older), investment in reproduction would hold greater fitness benefits than maintenance of swimming capacity.

Acknowledgements. The present study was supported by grants to H.G. from the Réseau Aquacole du Québec and from the NSERC. A.A.L. held a scholarship from FQRNT for the duration of her master's studies. We wish to thank Xavier Janssoone for his careful and thorough technical and analytic work, and Trish Schulte for providing us with phosphoarginine during the period when this interesting molecule was no longer commercially available.

\section{LITERATURE CITED}

Alexander RM (1966) Rubber-like properties of inner hingeligament of Pectinidae. J Exp Biol 44:119-130

Anderson EJ, MacGillivray PS, DeMont ME (1997) Scallop shells exhibit optimization of riblet dimensions for drag reduction. Biol Bull 192:341-344

Arsenault DJ, Himmelman JH (1996) Ontogenic habitat shifts of the Iceland scallop, Chlamys islandica (Muller, 1776), in the northern Gulf of St Lawrence. Can J Fish Aquat Sci 53:884-895

Bailey DM, Peck LS, Bock C, Pörtner HO (2003) High-energy phosphate metabolism during exercise and recovery in temperate and Antarctic scallops: an in vivo P-31-NMR study. Physiol Biochem Zool 76:622-633

Barbeau MA, Scheibling RE (1994) Behavioral mechanisms of prey size selection by sea stars (Asterias vulgaris Verrill) and crabs (Cancer irroratus Say) preying on juvenile sea scallops (Placopecten magellanicus (Gmelin)). J Exp Mar Biol Ecol 180:103-136

Brand AR (1991) Scallop ecology: distribution and behavior. In: Shumway SE (ed) Scallops: biology, ecology and aquaculture. Elsevier, Amsterdam, p 517-584

$>$ Brokordt KB, Himmelman JH, Guderley HE (2000a) Effect of reproduction on escape responses and muscle metabolic capacities in the scallop Chlamys islandica (Muller, 1776). J Exp Mar Biol Ecol 251:205-225

Brokordt KB, Himmelman JH, Nusetti OA, Guderley HE (2000b) Reproductive investment reduces recuperation from exhaustive escape activity in the tropical scallop Euvola zizac. Mar Biol 137:857-865

Brokordt KB, Fernandez M, Gaymer CF (2006) Domestication reduces the capacity to escape from predators. J Exp Mar Biol Ecol 329:11-19

Caddy JF (1968) Underwater observations on scallop Placopecten magellanicus: behaviour and drag efficiency. J Fish Res Board Can 25:2123-2141

Caddy JF (1972) Progressive loss of byssus attachment with size in the sea scallop, Placopecten magellanicus (Gmelin). J Exp Mar Biol Ecol 9:179-190

Chih CP, Ellington WR (1983) Energy-metabolism during contractile activity and environmental hypoxia in the phasic adductor muscle of the bay scallop, Argopecten irradians concentricus. Physiol Zool 56:623-631

Childress JJ, Somero GN (1990) Metabolic scaling - A new perspective based on scaling of glycolytic enzyme activities. Am Zool 30:161-173

> Dadswell MJ, Weihs D (1990) Size-related hydrodynamic characteristics of the giant scallop, Placopecten magellanicus (Bivalvia, Pectinidae). Can J Zool 68:778-785

Ellington WR (1983) The recovery from anaerobic metabolism in invertebrates. J Exp Zool 228:431-444
Elner RW, Jamieson GS (1979) Predation of sea scallops, Placopecten magellanicus, by the rock crab, Cancer irroratus, and the American lobster, Homarus americanus. J Fish Res Board Can 36:537-543

Emmett B, Hochachka PW (1981) Scaling of oxidative and glycolytic enzymes in mammals. Respir Physiol 45:261272

Fleury PG, Janssoone X, Nadeau M, Guderley H (2005) Force production during escape responses: sequential recruitment of the phasic and tonic portions of the adductor muscle in juvenile sea scallop, Placopecten magellanicus (Gmelin). J Shellfish Res 24:905-911

> Gade G (1983) Energy-metabolism of arthropods and mollusks during environmental and functional anaerobiosis. J Exp Zool 228:415-429

Goolish EM (1991) Aerobic and anaerobic scaling in fish. Biol Rev Camb Philos Soc 66:33-56

Gould SJ (1971) Muscular mechanics and the ontogeny of swimming in scallops. Palaeontology 14:61-94

- Guderley H, Janssoone X, Nadeau M, Bourgeois M, Cortes HP (2008) Force recordings during escape responses by Placopecten magellanicus (Gmelin): seasonal changes in the impact of handling stress. J Exp Mar Biol Ecol 355: 85-94

Hochachka PW, Somero GN (2002) Biochemical adaptations: mechanism and process in physiological evolution. Oxford University Press, New York

Hulbert AJ, Else PL (2005) Review: membranes and the setting of energy demands. J Exp Biol 208:1593-1599

Kraffe E, Tremblay R, Belvin S, LeCoz JR, Marty Y, Guderley $H$ (2008) Effect of reproduction on escape responses, metabolic rates and muscle mitochondrial properties in the scallop Placopecten magellanicus. Mar Biol 156: 25-38

Lafrance M, Cliche G, Haugum GA, Guderley H (2003) Comparison of cultured and wild sea scallops Placopecten magellanicus, using behavioral responses and morphometric and biochemical indices. Mar Ecol Prog Ser 250: 183-195

Legault C, Himmelman JH (1993) Relation between escape behavior of benthic marine invertebrates and the risk of predation. J Exp Mar Biol Ecol 170:55-74

Legendre P, Legendre L (1998) Numerical ecology. Elsevier, Amsterdam

> Livingstone DR, Dezwaan A, Thompson RJ (1981) Aerobic metabolism, octopine production and phosphoarginine as sources of energy in the phasic and catch adductor muscles of the giant scallop Placopecten magellanicus during swimming and the subsequent recovery period. Comp Biochem Physiol B 70:35-44

Mackay J, Shumway SE (1980) Factors affecting oxygen-consumption in the scallop Chlamys delicatula (Hutton). Ophelia 19:19-26

> Manuel JL, Dadswell MJ (1993) Swimming of juvenile sea scallops, Placopecten magellanicus (Gmelin)-A minimum size for effective swimming. J Exp Mar Biol Ecol 174:137-175

Naidu KS, Meron S (1986) Predation of scallops by American plaice and yellowtail flounder. In: Canada FaO (ed) Canadian Atlantic Fisheries Scientific Advisory Committee Research Document 86/62, $25 \mathrm{p}$

Naidu KS, Robert G (2006) Fisheries sea scallop, Placopecten magellanicus. In: Shumway SE, Parsons GJ (eds) Scallops: biology, ecology and aquaculture. Elsevier, Amsterdam, p 869-905

Pérez HM, Janssoone X, Guderley H (2008) Tonic contractions allow metabolic recuperation of the adductor muscle 
during escape responses of giant scallop, Placopecten magellanicus. J Exp Mar Biol Ecol 360:78-84

Pérez HM, Janssoone X, Côté C, Guderley H (2009) Comparison between in vivo force recordings during escape responses and in vitro contractile capacities in the sea scallop, Placopecten magellanicus. J Shellfish Res 28: 491-495

Scherrer B (2009) Biostatistique. Gaëtan Morin éditeur ltée, Montréal

Schmidt M, Philipp EER, Abele D (2008) Size and agedependent changes of escape response to predator attack in the queen scallop, Aequipecten opercularis. Mar Biol Res 4:442-450

Soemodihardjo S (1974) Aspect of the biology of Chlamys opercularis (L) (Bivalvia) with comparative notes on four allied species. PhD thesis, University of Liverpool, Liverpool

Somero GN, Childress JJ (1980) A violation of the metabolism-size scaling paradigm: activities of glycolytic enzymes in muscle increase in larger size-fish. Physiol Zool 149:319-333

Tabachnick BG, Fidell LS (1989) Using multivariate Statistics. Harper Collins Publisher, New York, NY

Thayer CW (1972) Adaptive features of swimming monomyarian bivalves (Mollusca). Form and Function 5:1-32

Thomas GE, Gruffydd LD (1971) The type of escape reactions

Editorial responsibility: Judith Grassle,

New Brunswick, New Jersey, USA elicited in the scallop Pecten maximus by selected sea-star species. Mar Biol 10:87-93

Thompson RJ, Livingstone DR, De Zwaan A (1980) Physiological and biochemical aspects of the valve snap and valve closure responses in the giant scallop, Placopecten magellanicus. I. Physiology. J Comp Physiol A Neuroethol Sens Neural Behav Physiol 137:97-104

Tremblay I, Guderley HE, Frechette M (2006) Swimming performance, metabolic rates, and their correlates in the Iceland scallop, Chlamys islandica. Physiol Biochem Zool 79:1046-1057

Trueman ER (1953) Observations on certain mechanical properties of the ligament of Pecten. J Exp Biol 30:453-467

Viant MR, Rosenblum ES, Tjeerdema RS (2001) Optimized method for the determination of phosphoarginine in abalone tissue by high-performance liquid chromatography. J Chromatogr A 765:107-111

Wilkie DR (1977) Metabolism and size. In: Pedley TJ (ed) Scale effects in animal locomotion, Vol 1. Academic Press, New York

Zar JH (1974) Biostatistical analysis. Prentice-Hall, Englewood Cliffs, NJ

Zwaan A, Thompson RJ, Livingstone DR (1980) Physiological and biochemical aspects of the valve snap and valve closure responses in the giant scallop Placopecten magellanicus. 2. Biochemistry. J Comp Physiol B 137:105-114

Submitted: November 3, 2010; Accepted: March 29, 2011

Proofs received from author(s): June 27, 2011 